\title{
SOCIAL NETWORKS: ADVANTAGES AND OPPORTUNITIES
}

\author{
Ion-Costel-Marius BĂLŢOI \\ Bucharest University of Economic Studies, Romania \\ marius.baltoi@ie.ase.ro
}

\begin{abstract}
With technological development, social networks have increased exponentially, giving people more and more opportunities. The purpose of the article is to highlight the benefits and opportunities that social networks offer to individual users or businesses. Therefore, it used a qualitative research methodology based on existing resources. The first part presents a statistical analysis of the characteristics of the public that uses the social networks, as well as the devices used by them. Next, the paper presents the benefits of social networks and an analysis of technologies that can be integrated into new social networking features. Among these new technologies, standouts electronic payment engines or emerging technologies (artificial intelligence, facial recognition, motion sensors).
\end{abstract}

Keywords: emerging technologies, electronic payments, social networks

JEL classification: O30, O35, Q55

DOI: $10.12948 / \mathrm{ie} 2019.04 .15$

\section{Introduction}

Since its advent, the Internet has forever changed the way people communicate. Due to the many advantages it offers, the Internet has become one of the most widely used services worldwide. Beginning as a research project, the Internet currently includes all interconnected global networks operated by governmental organizations, industry, academia or other private entities [1]. Among the factors that favored the accelerated development of the Internet are both the development of web / mobile technologies and the development of telecommunication infrastructure. Therefore, the Internet became accessible to $55.1 \%$ of the world's population in the middle of 2018 [2].

People's need to communicate has favored the appearance and development of social networks. Since the beginning, people have included social networks in their daily habits. Most new emerging social networks integrate specific functions and help people connect on the basis of common interests or on the basis of their activities. Certain social networks are addressed to the general public, while others address racial, sexual or religious minorities.

Social networks are new information and communication tools such as mobile connectivity, blogging and photo/video sharing. So today, platforms like Facebook, Twitter, Instagram, WhatsApp, Skype or Pinterest are always present. Depending on the geographical area or the cultural specificity, social platforms have been imposed in certain areas of the world. Therefore, Facebook is a leader in America, Europe, Africa, Australia and South Asia, while platforms such as VKontakte (Russia) or QZone (China) have targeted a geographical area.

Currently there are thousands of social networks that offer various services to users, from managing personal profile and friends list, distributing content (text, images, video content) to friends or a wider audience within communities, messaging and to product and business promotion, service or product purchases.

In this paper, a qualitative research is carried out, analyzing various resources such as present research articles, scientific communications or online resources that address the proposed topic for research. 
The analysis presents the benefits that social networks bring to both people (communication, information, education etc.) as well as business (promoting products and services, communication with clients etc.). Since their appearance, the main advantage of social networking has been to support people's communication. This article also analyzes a number of emerging technologies in the market at the moment and offers a number of benefits. The analysis will also propose a number of new functionalities that can be integrated into social networks.

Section 3 presents the benefits that social networks offer to both individual users and businesses that are present in the online environment. The benefits of social networks will be pursued at conceptual level as well as the interpretation of various existing statistics at the moment. Section 4 aims to address the opportunities and directions of development of social networks; a series of features are presented, whose implementation is in the early stages and new development directions within social networks are proposed through which both individual users and companies benefit. The paper ends with a conclusions section that presents and interprets the results obtained and creates the context for further research.

\section{Social networks}

With the increasing impact on users, social networks have become an important subject in the field of research. Therefore, in [3] social networks were defined as "web-based services that allow individuals to construct a public or semi-public profile within a bounded system, articulate a list of other users with whom they share a connection and view and traverse their list of connections and those made by others within the system". According to the study presented in [4], the greatest benefit of social networks is the exchange of information and communications.

As for the global social networks in January 2019, as presented in Figure 1, Facebook was used by 2.271 billion users; almost a third of the planet's inhabitants have a Facebook account. Facebook is followed by YouTube (the video sharing platform) with 1.9 billion users, WhatsApp (messaging platform) with 1.5 billion users worldwide. Facebook Messenger, the Facebook's messaging platform has 1.3 billion users and the messaging platform WeChat has a little over 1 billion users worldwide. Instagram, the image sharing platform had 1 billion users in October 2018. Therefore, out of the total of 6 platforms, it is noted that 3 of them are specialized in the provision of messaging and communications services [5].



Figure 1. Social networks users, January 2019 [7]

To analyze the context in which social networks have evolved, as well as future opportunities in terms of number of users and actual development, we can make an analysis of statistics on "social media".

Social Media can be defined as a set of communication channels through which users create communities

and share information, ideas, personal messages and other content (photos, videos, music, etc.). Among the various types of social media, we can list dedicated sites and applications for social networks, forums or microblogging.

Table 1 shows data provided by WeAreSocial (organization for social networks monitoring) and highlights a comparative analysis of the penetration rate of social networks in the world 
and in Romania. We can note that relative indicators in Romania indicate a better rate of adoption of the technology by the population (internet, number of social media users, telephony users and social media usage on the mobile device).

Table 1. Comparative analysis worldwide - Romania [6]

\begin{tabular}{|c|c|c|c|c|}
\hline & $\begin{array}{c}\text { Number of users } \\
\text { worldwide } \\
\text { (billions) }\end{array}$ & $\begin{array}{c}\text { Penetration } \\
\text { rate } \\
\text { worldwide }\end{array}$ & $\begin{array}{c}\text { Number of users } \\
\text { Romania (millions) }\end{array}$ & $\begin{array}{c}\text { Penetration } \\
\text { rate } \\
\text { Romania }\end{array}$ \\
\hline Total population & 7.593 & $53 \%$ & 19.63 & $70 \%$ \\
\hline Internet users & 4.021 & $42 \%$ & 10.00 & $51 \%$ \\
\hline $\begin{array}{c}\text { Active social } \\
\text { media users }\end{array}$ & 3.196 & $68 \%$ & 15.97 & $81 \%$ \\
\hline $\begin{array}{c}\text { Unique mobile } \\
\text { users }\end{array}$ & 5.135 & $39 \%$ & 8.90 & $45 \%$ \\
\hline $\begin{array}{c}\text { Active mobile } \\
\text { social users }\end{array}$ & 2.958 & & \\
\hline
\end{tabular}

In the world, out of a total population of 7.59 billion people in January 2018, approximately 4.021 billion people had access to the Internet or $53 \%$ of the world's total population. It can also be noticed that 3.19 billion (42\%) of the world's population has an account on at least one of the social networks. In terms of phone use, 5.13 billion people $(68 \%$ of the world's population) own such a device and 2.95 billion people interact online using mobile devices.

At the Romanian level, of the total population of 19.63 million people (of which $55 \%$ live in the urban area), 13.74 million have access to the Internet, accounting for $70 \%$ of the total population. Of the total population, about 10 million people (51\% of the total population) have at least one account on Social Media platforms. It can also be noted that $15.97 \%$ (81\% of the total number of inhabitants) own a mobile device and 8.90 million (or $45 \%$ of the number of inhabitants) also use it to interact within social platforms.

As a conclusion, previous statistics present a high degree of accessibility of social networks and show people's willingness to adopt new technologies.

\section{Benefits of social networks}

The way technology evolves helps social networks become more and more present in people's lives, and their advantages attract more and more users, both individuals and companies interested in business growth (Table 2). Benefits to users can highlight connectivity from anywhere in the world, fast communication with friends, creating communities based on interests, sharing information in real time, viewing information based on interests, and more.

Table 2. Benefits of social networks

\begin{tabular}{|c|c|}
\hline For individuals & For business \\
\hline connectivity from anywhere & communication channel with clients \\
\hline fast communication & customer support \\
\hline $\begin{array}{c}\text { information and communities based on } \\
\text { interests }\end{array}$ & $\begin{array}{c}\text { promoting the content to the interested } \\
\text { audience }\end{array}$ \\
\hline sharing information in real time & brand growth on the market \\
\hline voice and video streams & customer data source \\
\hline
\end{tabular}

Internet network development has supported these social networking benefits, and networks such as Facebook, LinkedIn, Instagram help people stay up-to-date. Each of these networks 
helps people increase their number of friends, build new business connections, and find new opportunities (personal, professional, business, etc.).

Communicating quickly with anyone, anywhere and anytime has become a basic need of modern man. The barriers related to physical distance have disappeared and the development of technology and social networks made it possible to communicate with family and friends from anywhere, free of charge.

Instant messaging services and VoIP systems implement real-time communication between the users. Instant messaging allows the exchange of information between two people or a group of people, and their development has allowed the exchange of voice and video streams. The environments that use VoIP systems (Skype, Ventrilo) increase the social presence [7].

The appearance of communities within social networks facilitates access to information based on common interests (habits, lifestyles, activities, passions, etc.), cohesion being a common value. Communities of social networks also support information sharing within the group. Within communities online, influence is shown on others. It is considered that the influence is a bidirectional concept: the opinion of a member can influence the rest of the members and the general opinion of the members influences the individual opinion of a member [8].

Besides the advantages offered to individual users, social networks also address to business. Whether we are talking about commerce, banking, education, health, social networks are the most important communication channel with clients because of the easy communication and permanent interaction with them. According to statistics [9], 80\% of social network users are looking at least at one business page and $75 \%$ of them visit the business site after viewing the post. Also, through social networks, companies can provide remote customer support.

In terms of growing a strong brand on the market, social networks increase brand awareness for new products with potential (60\% of Instagram users discover new products on the platform [9]). They also offer the possibility of increasing consumer confidence through brand promotion due to the innovative spirit that it brings on the market and can have a major impact especially in Business to Business eCommerce (B2B).

One of the greatest benefits that social networks offer to companies is represented by addressing to a particular segment of the population, whether they are demographics (for example, country, geography, age, sex, environment, etc.) or the specific characteristic of consumer behavior (interests, habits, desires, etc.). In this way, promoted content is distributed only to the interested audience and the success rate of promotional campaigns increases exponentially. Also, social networks are an important way of collecting data for various purposes. For example, real-time data about customers can be collected (e.g., demographics data to adapt the product promotion strategy).

\section{Opportunities and directions for developing social networks 4.1 Electronic payments}

In [10], electronic payments via mobile phone are classified of in two major categories: micropayments (value below 10 euro, e.g. tickets for public transport or small shopping) and macropayments (value more than 10 euros, e.g. online shopping). Therefore, micropayments can be made directly by SMS sent from the mobile phone; merchants avoid paying through debit/credit cards due to high commissions. Macropayments are a real challenge for electronic payment providers because they need strong security to avoid fraud.

Integration of electronic payments within social networks brings a number of benefits, among which we can enumerate increased security due to the increase of security levels, merchants having no access to card data, very low fees for users, universality due to functioning on any platform or growth of consumer satisfaction [11]. 
Major social networks are trying to keep pace with technology development and integrate as many functionalities to improve users' lives. Therefore, social networks begin to include various payment systems: whether they are social networking purchases or payments made through related transfer systems.

In order to capitalize on the opportunities offered by social networks, providers of electronic payment services are allied with social networking companies. In this way, they provide the latest technologies to simplify the acquisition, transfer, payment processes and social networks ensure the promotion of new services and bring new users. At present, there is a tendency for hardware components to be used in payment processes, such as camera (photo capture and using applications for Optical Character Recognition (OCR), QR Codes etc.), NFC (proximity of the compatible mobile device and making payments) or fingerprint sensors (to authenticate and authorize transactions).

Electronic payment systems are being tested by large social networks and instant messaging services. Companies such as Facebook, Snapchat or Microsoft are using this functionality on certain markets. For example, in Australia, Facebook Messenger has a payment service that allows users to transfer money to friends, making payments within 1-3 days. Snapcash also works with Visa or MasterCard cards issued in the United States (payments are limited to \$ 250 , and after verification of identity, the amount is extended to $\$ 2,500$ ). Skype users in the US, UK and Canada can use Skype Money, the functionality obtained following a partnership between Microsoft and PayPal.

The WeChat social network also offers facilities for money transfer, goods and services payments or bill payments. WeChat allows users to transfer money without commissions between friends, but it applies various fees for withdrawals or for operations involving crossborder transfer; transactions are made within one day. WeChat Pay services can be integrated for QR Code payments (Quick Pay), on eCommerce sites or on mobile applications.

The development of mobile devices and the need for users to use financial functions in everyday life has led to the emergence of e-wallets [12]. They work either as an integrated application or can be installed by the user and store information about credit or debit cards, discount coupons, rewards received, etc. Among mobile wallets developed by renowned companies, we can list Google Wallet, Apple Passbook, Venmo, PayPal.

Besides the big companies that are developing electronic payment solutions, a number of fintech companies are developing that offer easy-to-use financial products and services at low cost. They deliver application programming interface (API) components. APIs allow startups to develop quickly innovative products that involve electronic payments. With the introduction of the PSD2 directive, financial institutions are required to provide information to third parties through these components, so fintech companies have a great opportunity to develop and market innovation. API products can include Dwolla, Stripe or Payoneer and on the Romanian market we can notice PayU, 2Checkout or Orange Money.

The electronic payment revolution integrates payments using NFC (Near Field Communication) technology, a fast, secure and easy-to-use technology that grows both in Europe and the United States. The way NFC technology works is to bring together two NFCenabled devices that can change payment information (details of the payer, payment amount, details of the payee, etc.) via radio waves when they are at a small distance from each other. NFC is one of the safest ways to pay because a biometric verification is performed to authenticate payment and the risk of fraud is completely eliminated [13].

According to McKinsey \& Company's global report [14], revenue from electronic payments will exceed $\$ 2$ trillion by 2020, after an increase of about $11 \%$ in recent years and more than $\$ 3$ trillion over the next five years. Increasing the number of transactions creates growth opportunities for all the actors involved due to the advantages described above. 
www.conferenceie.ase.ro

\subsection{Emerging technologies}

Technology has transformed people's way of life and made possible new experiences for people. Whether it is technology emerging in recent times (e.g. the global positioning system GPS) or emerging technologies, each one has a role in changing people's way of life.

The term "emerging technology" can be considered a relative term. It refers to a new technology or is being developed / will be developed in the coming years. This will help to change the social or business environment. In the category of emerging technologies, we can consider artificial intelligence, Internet of Things, smart devices, cloud computing, etc.

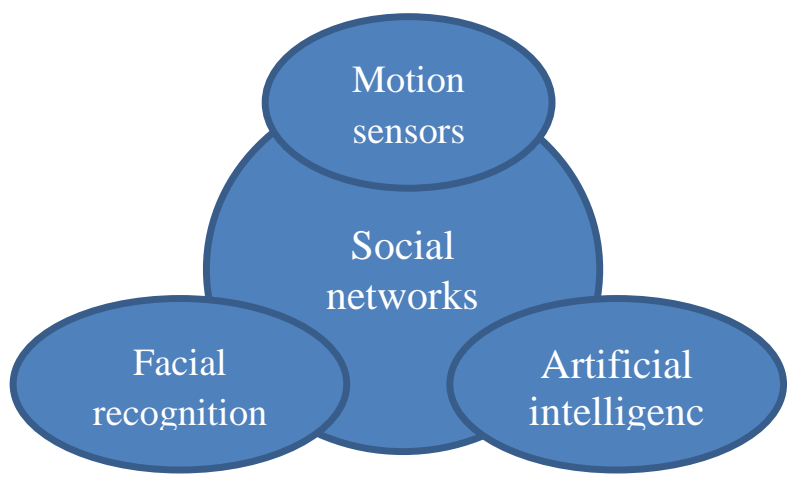

Figure 2. Social networks and emerging technologies

Facial recognition is the feature of a system which is capable of checking any person by comparing an image stored with a real-time image or another digital image. Currently, facial recognition systems are used to increase security, but also to provide support to social network users in recognizing friends.

The facial recognition process consists of two steps: face detection (detecting pixels in the image that contain information about the person's face) and face recognition (analysis of the part of the image detected at the previous stage). For face detection, algorithms like Haar Cascade [15] can be used (an algorithm that uses the change of contrast values between the adjacent pixel groups). Face recognition raises a number of issues, including illumination (any change in light can lead to the loss of information in each pixel), position (rotation of the person's face can affect the precision of recognition), passage of time (a person's physiognomy changes over time) [16].

Recent advances in technology allow the integration of motion sensors within social networks, so each use of social networks gives them information about activity in the online environment, ranging from the length of time spent to daily habits or passions. Motion sensors detect objects and people's movements and automatically transmit information to adjacent systems. Through motion sensors, it is possible to collect data about physical activity, time spent at home or at work, managing your favorite activities, etc.

Sensors have the ability to collect a large amount of data from one or more users, data that needs to be stored and processed continuously. Due to the large number of users, there is a problem of storage of information, so it is not recommended to store raw information [17].

Artificial intelligence is considered by most social networks to be the way forward for business progress. Facebook social network has invested in artificial intelligence since 2013 and research results are based on automatic tagging of friends using neural networks and recognizing images, making it easier to find new friends. Facebook also uses artificial intelligence to better filter news streams within the network. Following the recent scandals involving Cambridge Analytics, artificial intelligence has been identified as a way to solve many of the issues with fake news [18]. 
Besides Facebook, other social networks like LinkedIn or Pinterest have integrated artificial intelligence into their own functionalities. For example, LinkedIn uses artificial intelligence algorithms to estimate which candidates are best suited to open jobs and highlights who are more likely to answer or who are looking for new opportunities for professional development [19]. Pinterest can identify objects within the image and make recommendations about products. Based on previous searches, Pinterest retains user preferences and future searches will be personalized based on them so that the results are as relevant [20].

\section{Conclusions}

Social networks have become indispensable nowadays. Technological development, the Internet coverage in the world, access to increasingly powerful devices, the need to communicate quickly and anywhere have supported the development of social networks all over the world. Statistics show that social networks are the most used applications on mobile devices. For example, on April 2018, 88\% of Facebook users accessed the social networking platform on mobile devices and at the US level the percentage of mobile users was $68 \%$ [21]. Also, the exponential growth of the number of social network users is due to the many benefits they bring to people, including increasing awareness, communicating with friends, keeping upto-date on the latest information about friends (benefits for people) or promoting products and services, providing customer support and information in a faster way and through a direct interaction (business benefits).

Existing social networks currently provide the basis for developing and integrating new functionalities within them. We can mention features that include electronic payments (whether we are talking about shopping through social networks, managing your own cards or accounts or transferring money through instant messaging applications). Social networks also integrate a series of emerging technologies such as facial recognition (photo recognition or for increasing security), artificial intelligence (personalized newsfeed management, automatic tagging based on facial recognition) or motion sensors (taking a user's location via GPS sensors).

The research will continue with several studies related to electronic payment systems integration within social networks, as well as the technologies by which the development of a functional prototype could be possible.

\section{Acknowledgement}

This paper was co-financed by The Bucharest University of Economic Studies during the PhD program.

\section{References}

[1] Miniwatts Marketing Group, "Internet growth statistics," 18 December 2018. [Online]. Available: https://www.internetworldstats.com/emarketing.htm. [Accessed 20 February 2019].

[2] Miniwatts Marketing Group, "Internet usage statistics," 18 December 2018. [Online]. Available: https://www.internetworldstats.com/stats.htm. [Accessed 20 February 2019].

[3] D. M. Boyd and N. B. Ellison, "Social Network Sites: Definition, History, and Scholarship," Journal of Computer-Mediated Communication, vol. 13, no. 1, pp. 210-230, 2007.

[4] M. Drahošová and P. Balco, "The analysis of advantages and disadvantages of use of social media," in The 7th International Symposium on Frontiers in Ambient and Mobile Systems (FAMS 2017), Porto, 2017. 
[5] Statista, "Global social networks ranked by number of users 2019," January 2019. [Online]. Available: https://www.statista.com/statistics/272014/global-social-networks-ranked-bynumber-of-users/. [Accessed 20 February 2019].

[6] We Are Social, "Digital in 2018 Global Overview," 29 January 2018. [Online]. Available: https://www.slideshare.net/wearesocial/digital-in-2018-global-overview86860338?ref=https://digitalreport.wearesocial.com/. [Accessed 20 February 2019].

[7] K. Musial and P. Kazienko, "Social networks on the Internet," World Wide Web, vol. 16, no. 1, p. 31-72, November 2012.

[8] D. W. McMillan and D. M. Chavis, "Sense of Community: A Definition and Theory," Journal of Community Psychology, vol. 14, 1986.

[9] T. Clarke, "22+ Stats That Marketers Can't Ignore This Year," 5 March 2019. [Online]. Available: https://blog.hootsuite.com/instagram-statistics/. [Accessed 7 March 2019].

[10] F. Liebana, F. Munoz-Leiva and J. Sanchez-Fernandez, "Overview of Mobile Payment: Technologies and Security," in Electronic Payment Systems for Competative Advantage in E-Commerce, IGI Global, 2014, p. 31.

[11] A. Beikverdi, I. Kim and J. Song, "Centralized payment system using social networks," in IEEE Fourth International Conference on Big Data and Cloud Computing, Sydney, 2014.

[12] W. Kenton, "Mobile Wallet," Investopedia, 3 March 2018. [Online]. Available: https://www.investopedia.com/terms/m/mobile-wallet.asp. [Accessed 7 March 2019].

[13] Bijlipay, "NFC Payments: How They Are Set to Change the Indian Payments Landscape," [Online]. Available: https://bijlipay.co.in/blog/nfc-payments-set-changeindian-payments-landscape/. [Accessed 01 March 2019].

[14] "Global payments 2018: A dynamic industry continues to break new ground," McKinsey \& Company, 2018.

[15] K. More, P. Kadam, A. Jadhav and D. Dalgade, "Face Authentication Application for Social Networking Site," International Journal of Computer Science and Mobile Computing, vol. 4, no. 3, pp. 430-433, 2015.

[16] J. Fajfr, "The basics of face recognition," 20 Octomber 2011. [Online]. Available: https://blog.octo.com/en/basics-face-recognition/. [Accessed 01 March 2019].

[17] C. Aggarwal, "Integrating Sensors and Social Networks," in Social Network Data Analytics, Springer, 2011, pp. 379-412.

[18] O. Egorsheva, "The Impact of Artificial Intelligence on Social Media," 1 August 2018. [Online]. Available: https://www.martechadvisor.com/articles/machine-learning-ampai/the-impact-of-artificial-intelligence-on-social-media/. [Accessed 25 February 2019].

[19] A. Smith, "Why the Future of Social Media Will Depend on Artificial Intelligence," 13 April 2018. [Online]. Available: https://www.smartdatacollective.com/future-socialmedia-depend-artificial-intelligence/. [Accessed 28 February 2019].

[20] F. Nikolic, "How do social networks use artificial intelligence?," 21 September 2018. [Online]. Available: https://www.quora.com/How-do-social-networks-use-artificialintelligence. [Accessed 2 March 2019].

[21] A. Dogtiev, "Facebook Revenue and Usage Statistics (2018)," 4 May 2018. [Online]. Available: http://www.businessofapps.com/data/facebook-statistics/. [Accessed 25 February 2019]. 